\title{
La Ley 30/2007, de Contratos del sector público y su influencia en el régimen de contratación de las fundaciones del sector público andaluz
}

\author{
M anuel M esa Vila \\ Jefe Área. Secretaría General \\ Centro de Estudios Andaluces
}

\begin{abstract}
SUMARIO: I. INTRODUCCIÓN. II. SITUACIÓN ANTERIOR. III. ÁMBITO SUBJETIVO DE LA LEY 30/ 2007. IV. CONTRATOS ADMINISTRATIVOS Y CONTRATOS PRIVADOS. V. DELIMITACIÓN DE LOS TIPOS CONTRACTUALES. VI. DISPOSICIONES GENERALES SOBRE LA CONTRATACIÓN DEL SECTOR PÚBLICO. 1. Necesidad e idoneidad del contrato. 2. Plazo de duración de los contratos. 3. Libertad de pactos. 4. Contenido mínimo del contrato. 5. Perfección de los contratos. 6. Lugar de celebración del contrato. 7. Remisión de información a efectos estadísticos y de fiscalización. 8. El recurso especial en materia de contratación. 9. Registro de contratos del sector público. 10. Contratación con empresas de trabajo temporal. 11. Cómputo de plazos. VII. PARTES EN EL CONTRATO. VIII. OBJETO, PRECIO, CUANTÍA Y GARANTÍA DEL CONTRATO. IX. PREPARACIÓN DE LOS CONTRATOS. X. ADJUDICACIÓN DE LOS CONTRATOS. 1. Los principios que rigen la adjudicación. 2. El procedimiento de contratación. 3. La garantía de efectividad de los principios de contratación. 4. Sobre la forma de adjudicación. 5. Plazos. 6. Racionalización de las formas de contratación. XI. EL PERFIL DEL CONTRATANTE. XII. EFECTOS, CUMPLIMIENTO Y EXTINCIÓN DE LOS CONTRATOS. XIII. CONCEPTO Y CARACTERÍSTICAS DE LAS FUNDACIONES DEL SECTOR PÚBLICO ANDALUZ EN LA LEY 9/ 2007, DE ADMINISTRACIÓN DE LA JUNTA DE ANDALUCÍA.
\end{abstract}

\section{INTRODUCCIÓN}

La Ley 30/ 2007, de 30 de octubre, de Contratos del Sector Público, surge como respuesta a un mandato comunitario de transposición al ordenamiento jurídico español de la Directiva 2004/ 18/ CE del Parlamento Europeo y del Consejo, de 31 de marzo de 2004, sobre coordinación de los procedimientos de adjudicación de los contratos públicos de obras, suministros y 
servicios. Esta Directiva sustituye, refunde e introduce importantes cambios a las anteriores Directivas (92/50/ CEE sobre contratos públicos de servicios, 93/36/ CEE, sobre contratos públicos de suministros y 93/37/ CEE, sobre contratos públicos de obras).

Pero, además de cumplir con el imperativo comunitario, el legislador español ha aprovechado la ocasión para mejorar la legislación hasta ahora vigente y para superar ciertos problemas que la experiencia de aplicación ha puesto de manifiesto.

La normativa anterior (Real Decreto Legislativo 2/ 2000, de 16 de junio, por el que se aprueba el Texto Refundido de la Ley de Contratos de las Administraciones Públicas), tenía como rasgos esenciales de su arquitectura los siguientes:

- Regulaba el contrato de la Administración Pública: de la Administración General del Estado y de las demás Administraciones.

- Se centraba en el contrato administrativo de la Administración Pública.

- Las necesidades de regular la contratación de otros sujetos del sector público se resuelvían mediante dos deficiencias técnicas importantes: por un lado, la extensión parcial de su regulación a ciertos contratos sujetos a la normativa comunitaria y, por otro, el sometimiento del resto de contratos del sector público a ciertos principios que debían regir su adjudicación, sin especificar en ningún caso cómo debía traducirse la aplicación de esos principios.

- Su estructura era bipolar (desde la ley 13/ 1995) con dos partes diferentes (libros): una parte general, integrada por normas aplicables a todos los contratos y una parte especial, que recogía las peculiaridades de los contratos administrativos típicos.

La nueva ley es bien distinta y viene a resolver algunos de los grandes problemas derivados del régimen jurídico de los contratos del sector público. Principalmente y en la parte que nos afecta, la novedad más destacable es la contemplación expresa en el ámbito subjetivo de aplicación de las fundaciones públicas como entes pertenecientes al sector público, sometidos y regulados en la parte de la ley que directamente les afecta.

El contrato administrativo deja de ser el protagonista exclusivo y pasa a ser uno más de los regulados en el texto, con lo que nos encontramos ante una regulación "a la carta" en la que cada tipo de ente del sector público encuentra sus propias normas, con el consiguiente incremento de la seguridad jurídica merced a la eliminación de remisiones imprecisasy la clarificación de lasnormas de aplicación. 
Por otra parte, la ley incorpora las nuevas tecnologías de la información y las comunicaciones como herramientas básicas del sistema. Internet se convierte en el principal medio de publicidad y difusión de las convocatorias y licitaciones, en detrimento de los boletines oficiales y periódicos, que en determinados tipos de contratos pierden peso. Esto supondrá sin duda un incremento de la concurrencia y participación de las empresas y un abaratamiento en los costos derivados de los procedimientos de adjudicación, lo que mejorará la eficiencia de los entes instrumentales.

Por último, y para cerrar este capítulo introductorio, la publicación de la ley 30/ 2007 ha coincidido en el tiempo con la Ley 9/ 2007 de Administración de la Junta de Andalucía, que también ha introducido importantes novedades en el régimen jurídico de las fundaciones del sector público, aclarando conceptos y posiciones, y sentando las bases del funcionamiento de éstas y su situación en la Administración de la Junta de Andalucía.

\section{SITUACIÓN ANTERIOR}

El régimen jurídico de la contratación de bienes y servicios de las fundaciones del sector público andaluz viene exiguamente regulado en el artículo 57.4 de la Ley 10/ 2005 de Fundaciones de la Comunidad Autónoma de Andalucía.

“... A simismo, su contratación deberá ajustarse a la normativa básica estatal en la materia y a la que corresponda aprobar a la Comunidad Autón oma de Andalucía".

Este artículo ha constituido la base sobre la que construir el sistema de contratación, que por la remisión expresa de la ley se basaba en el Real Decreto Legislativo 2/ 2000, de 16 de julio, de Contratos de las Administraciones Públicas, y en concreto por la Disposición Adicional Sexta, que fue modificada por el art. 34.2 del Real Decreto Ley 5/ 2005, de 11 de marzo de reformas urgentes para el impulso de la productividad y para la mejora de la contratación pública, en virtud de la cual:

"Las sociedades mercantiles y las fundaciones del sector pú blico a que se refiere el apartado 1 del artículo 2, para los contratos no comprendidos en él, así como las restantes sociedades mercantiles en cuyo capital sea mayoritaria la participación directa o indirecta de las Administraciones Públicas o de sus organismos autónomos o en tidades de derecho público, se ajustarán en su actividad contractual a los principios de publicidad y concurrencia, salvo que la naturaleza de la operación a realizar sea incompatible con estos principios." 
El Real Decreto Ley 5/ 2005 consagra unos principios que de hecho ya se venían aplicando con anterioridad como principios inspiradores de la actividad de todos los entes instrumentales.

El problema no era la vigencia de los principios, algo que nadie discutía, sino que cada uno de los entes instrumentales tenía una peculiar forma de interpretarlos y aplicarlos. Para dar solución a este problema la Intervención General de la Junta de Andalucía publicó la Instrucción 3/ 2000, de 10 de febrero, sobre aplicación de los principios de publicidad y concurrencia en la contratación, que en un principio iba dirigida exclusivamente a las entidades recogidas en la redacción original de la Disposición Adicional Sexta de la Ley de Contratos: Sociedades mercantiles en cuyo capital sea mayoritaria la participación de las Administraciones Públicas; pero tras la reforma de la citada disposición hemos de entender también incluidas a las fundaciones del sector público andaluz.

La Instrucción 3/ 2000 no establece un protocolo de contratación que han de asumir y aplicar las empresas públicas, sino que recoge detalladamente aquellos aspectos concretos que la Intervención General va a tener en cuenta a la hora de realizar las comprobaciones necesarias para la elaboración de los informes de control financiero y control financiero permanente.

La intervención da por sentado que las empresas han de tener establecido y aprobado un protocolo que regule las competencias y procedimientos de contratación y que ese protocolo debe tener en cuenta los criterios de la Intervención General.

La instrucción establece que la comprobación del cumplimiento de los principios de publicidad y concurrencia a los que ha de ajustarse la actividad contractual de las sociedades se efectuará por los interventores actuantes a través de la verificación de una serie de exigencias relativas a:

- La rigurosa preparación de los proyectos, especificaciones financieras y técnicas, así como de los pliegos de condiciones que hayan de servir de soporte al contrato.

- La publicación, con la suficiente antelación, de invitaciones a participar en las contrataciones a efectuar, para su conocimiento por los posibles proveedores interesados.

La Ley de Contratos vigente establece en su artículo 2 que si se superan determinadas cantidades, excluido el IVA (Reforma de cantidades por O rden 
del Ministro de Hacienda 4110/ 05, de 29 de diciembre: Obras: 5.278.227 y Consultoría y asistencia, servicios y suministros: 211.129 ), las fundaciones del sector público vendrían obligadas a cumplimentar todas las exigencias recogidas en la ley en lo referido a:

- Capacidad de las empresas

- Publicidad

- Procedimientos de licitación

- Formas de adjudicación

La consecuencia más trascendente de esta disposición es la referida a publicidad comunitaria, la obligación de publicar en el DOUE la convocatoria, así como la obligatoriedad de la clasificación de los aspirantes.

La disposición adicional sexta también consagraba una excepción,

“... salvo quela naturaleza dela operación a realizar sea incompatible con estos principios".

La citada excepción también ha sido matizada: La regla cuarta de la Instrucción 3/ 2000 establece que la realización de actuaciones excepcionales en las que no se apliquen los principios, requerirá informe justificativo emitido por los órganos de dirección.

Por su parte, la regla tercera prevé la posibilidad de utilizar el procedimiento de contratación negociado sin publicidad, cuando concurran circunstancias análogas a las previstas en la ley de Contratos, pero aún utilizando este procedimiento es necesaria la solicitud expresa de tres ofertas.

Como se puede comprobar, se trata de un panorama bastante confuso, basado en la interpretación más o menos homogénea de los principios básicos de la contratación administrativa y que sin duda alguna aplaude con entusiasmo la aparición de la nueva ley que supone la definición y elevación a rango legal de un procedimiento de enorme relevancia en la gestión de las fundaciones del sector público.

\section{III. ÁMBITO SUBJETIVO DE LA LEY 30/ 2007}

Constituye, sin duda, la principal novedad de la ley y la principal aportación para sentar de una vez un régimen jurídico claro en la contratación de las fundaciones del sector público. 
Como dice la exposición de motivos de la ley en su párrafo segundo" (...) la normativa de contratación de sector público se ha construido al rededor del con trato de la Administración Pública y más específicamen te en torno al contrato administrativo de la Administración Pública. La necesidad de pautar la contratación de otros sujetos, se solventaba en este modelo bien mediante la extensión parcial de esta regulación, bien mediante la declaración de sometimiento de los restantes contratos del sector público a ciertos principios que debían presidir su adjudicación. Esta técnica de regulación pre sentaba los inconvenientes fundamentales de situar el régimen aplicable a los contratos no celebrados por Administraciones Públicas en un ámbito caracterizado por su indefinición..."

La indefinición jurídica es la nota fundamental que ha caracterizado la contratación pública de los entes instrumentales en general y de las fundaciones del sector público en particular.

La nueva ley viene a poner fin a esta situación ampliando el ámbito subjetivo de su aplicación y realizando una regulación "a la carta" del régimen jurídico de la contratación de cada uno de los entes que incluye. Se supera el término restrictivo de "Contratos de la Administración Pública" por el amplio "con tratos del sector público".

La ley distingue entre tres tipos de entes:

- Sector público, el más amplio concepto

- Administraciones Públicas, un subconjunto del anterior

- Poderes adjudicadores, un conjunto que agrupa a parte del primero y al segundo completo

La exposición de motivos los agrupa en:

- Administraciones públicas.

- Entes del sector público que, no teniendo el carácter de Administración Pública, están sujetos a la Directiva 2004/ 18/ CE, lo que en la anterior clasificación hemos denominado poderes adjudicadores.

- $\quad$ El resto de entes del sector público que no son Administración Pública ni están sujetos a la directiva 2004/ 18/ CE.

Las fundaciones del sector público aparecen expresamente mencionadas en el artículo 3.1.f) dentro de los entidades y organismosque forman parte del sector público: "las fundaciones que se constituyan con una aportación mayoritaria, directa 0 indirecta, de una o varias entidades in tegradas en el sector público, o cuyo pa- 
trimonio fundacional, con un carácter de permanencia, esté formado en más de un 50 $\%$ por bienes o derechos a portados o cedidos por las referidas entidades".

Definición ésta que prácticamente coincide con la de fundación del sector público andaluz que recoge el párrafo primero del artículo 55 de la Ley 10/ 2005, de 31 de mayo, de Fundaciones de la Comunidad Autónoma de Andalucía:

\begin{abstract}
"A los efectos de esta Ley, se consideran fundaciones del sector público dela Comunidad Autónoma de Andalucía tanto aquellas que se constituyan con una aportación mayoritaria, directa 0 indirecta, de la Administración de la Junta de Andalucía, sus organismos públicos o demás entidades 0 empresas de la Junta de Andalucía, como aquellas que su patrimonio fundacional, con un carácter depermanencia, estéformado en más de un cincuenta por ciento por bienes o derechos aportados o cedidos por dichas entidades.

Asimismo, serán consideradas fundaciones del sector público de la Comunidad Autónoma de Andalucía aquellas en las que la Administración de la Junta de Andalucía tenga una representación mayoritaria. Se entenderá que existe ésta cuando más de la mitad de los miembros de los órganos de administración, dirección o vigilancia de la fundación sean nombrados por la Junta de Andalucía, a través de cualquiera de sus instituciones, entidades, órganos, organismos au tón omos o empresas".
\end{abstract}

Este segundo párrafo quedaría encuadrado dentro del apartado h) del artículo 3.1 de la Ley 30/ 2007, que considera que forman parte del sector público cualesquiera entes, organismos o entidades con personalidad jurídica propia siempre que, entre otras cuestiones, uno o varios sujetos pertenecientes al sector público nombren a más de la mitad de los miembros de su órgano de administración, dirección o vigilancia.

Por tanto, identidad absoluta en lo que se entiende por fundación del sector público entre lo dispuesto por el legislador andaluz y el estatal.

Dado que estamos hablando del mismo tipo de entidades, hemos de ver si además de considerarse sector público, las fundaciones se encuadran dentro de la categoría de poderes adjudicadores.

Se consideran poderes adjudicadores (artículo 3.3) además de las Administraciones Públicas, todos los entes, organismos o entidades con personalidad jurídica propia que hayan sido creados específicamente para satiffacer necesidades de interés general que no tengan carácter industrial o mercantil, siempre que uno $o$ varios sujetos que deban considerarse poder adjudicador financien mayoritariamente su actividad, controlen su gestión o nombren a más de la mitad de los miembros de su órgano de administración, dirección o vigilancia. 
Con esta amplia definición entendemos que las fundaciones del sector público andaluz deben considerarse a los efectos de la Ley 30/ 2007 poderes adjudicadores, tanto aquellas que han sido creadas directamente por la Administración Autonómica o local, como aquellas que han sido creadas o son participadas o controladas por organismos autónomos, entidades públicas empresariales, universidades públicas, agencias o sociedades mercantiles en cuyo capital social sea mayoritaria la participación de entidades del sector público. Para realizar tal afirmación hemos de tener en cuenta que una de las notas características fundamentales de las fundaciones en general, es la de perseguir fines de interés general. La fundación no es una forma jurídica apropiada para albergar un carácter industrial o mercantil; para eso el ordenamiento jurídico prevé otras formas de personalidad jurídica: las sociedades mercantiles. Téngase en cuenta que los fines que han de perseguir las fundaciones están tasados en el artículo 3 de la Ley 10/2005, de fundaciones de la Comunidad Autónoma de Andalucía:

\footnotetext{
"Las fundaciones deberán persegu ir fines de interés gen eral como pueden ser, entre otros, los de defensa de los derechos humanos, de las víctimas del terrorismo y actos violentos, asistencia social e inclusión social, cívicos, educativos, culturales, científicos, deportivos, sanitarios, laborales, de fortalecimien to institucional, de cooperación para el desarrollo, de promoción del voluntariado y de respaldo a la igualdad de oportunidades en tre hombres y mujeres, o cualesquiera otros de análoga naturaleza, de promoción de la acción social, de defen sa del medio ambiente, y de fomen to de la economía social, de promoción y atención a las personas en riesgo de exclusión por razones físicas, sociales o culturales, de promoción de los valores con stitucionales y estatu tarios y de defensa de los principios democráticos, de fomento de la tolerancia, de desarrollo de la sociedad de la información, de investigación científica y desarrollo tecnológico, o de establecimiento de vínculos de solidaridad entre las personas y los territorios".
}

La pertenencia a esta categoría especial y novedosa de poder adjudicador tiene una enorme trascendencia práctica y cambia por completo el régimen jurídico de la contratación de las fundaciones del sector público, siéndole de aplicación directa una serie de preceptos de la nueva ley de contratos específicamente destinados a este tipo de entidades.

\section{CONTRATOS ADMINISTRATIVOS Y CONTRATOS PRIVADOS}

Los contratos del sector público pueden tener carácter administrativo o carácter privado.

Tienen carácter administrativo, en general y en el ámbito que nos interesa, los contratos celebrados por una Administración Pública. 
Tendrán la consideración de contratos de carácter privado los celebrados por los entes, organismosy entidades del sector público que no reúnan la condición de Administración Pública.

La distinción resulta fundamental para entender la sistemática de la ley, ya que en aplicación de la doctrina de los actos separables, se hace una primera gran distinción de la aplicabilidad de sus preceptos, y establece que los contratos administrativos se regirán en cuanto a su preparación, adjudicación, efectos y extinción, por la ley y su desarrollo reglamentario.

Además, la distinción adquiere otra dimensión, ya que cuando se actúa sometido a derecho privado, los entes intervienen desprovistos de todo privilegio o prerrogativa que otorga el derecho público a la Administración, como manifestación de la potestad general de autotutela de que goza en aras a una mejor protección del interés público que representan. Concretamente, ostenta las siguientes prerrogativas (artículo 194)

- De dirección, inspección y control

- De interpretación

- De modificación

- De anulación

- De resolución

- De suspensión de contratos.

Por su parte, a los contratos privados les serán de aplicación los preceptos de la ley en cuanto a su preparación y adjudicación. Sus efectos y extinción quedan fuera del ámbito de regulación de la ley que los remite al derecho privado.

Como consecuencia de lo anterior, el orden jurisdiccional contencioso administrativo será competente para resolver las cuestiones litigiosas relativas a los contratos administrativos, y el orden jurisdiccional civil lo será respecto de los contratos privados ( con la salvedad de los contratos sujetos a regulación armonizada).

Como conclusión podemos afirmar que los contratos celebrados por las fundaciones del sector público andaluz tendrán la consideración de contratos privados, quedando sometidos a lo establecido por la ley 30/ 2007 en lo relativo a los actos de preparación y adjudicación, quedando los efectos y extinción sometidos a derecho privado, siendo competencia del orden jurisdiccional civil las cuestiones litigiosas que pudieran surgir. 


\section{DELIMITACIÓN DE LOS TIPOS CONTRACTUALES} guientes:

Los contratos del sector público típicos que establece la ley son los si-

- Contrato de obras

- Contratos de concesión de obras públicas

- Contrato de gestión de servicios públicos

- Contrato de suministro

- Contrato de servicios

- Contrato de colaboración entre el sector público y privado

Con respecto a la legislación anterior, desaparece el contrato de consultoría y asistencia, que queda encuadrado dentro de la categoría de los contratos de servicios y aparece una nueva categoría: los contratos de colaboración entre el sector público y privado.

A las fundaciones del sector público, de los seis tipos contractuales, interesan sólo tres, ya que otros tres quedan excluidos explícita o implícitamente de su ámbito de actuación:

Tanto el contrato de gestión de servicios públicos como el contrato de colaboración entre el sector público y privado, está expresamente reservado a la Administración Pública (artículos 8 y 10) y excluido, por tanto, a otros entes del sector público.

Por su parte, en el contrato de concesión de obra pública no existe, como en los casos anteriores contemplados en el artículo dedicado a su definición (artículo 7), una reserva expresa a la Administración Pública. Sin embargo, en momentos posteriores del texto legislativo sí habla de Administración concedente (artículo 112). Podemos entender que con esta forma de expresarse el legislador ha querido realizar una reserva implícita a favor de la Administración Pública en la utilización de este tipo contractual; de no ser así hubiera utilizado una terminología menos excluyente y precisa (entidades del sector público, poderes adjudicadores). En cualquier caso, sea esta o no la intención del legislador, el contrato de concesión de obras públicas difícilmente entraría dentro de la esfera jurídica y de las atribuciones y posibilidades de las fundaciones del sector público andaluz.

Por tanto, nos quedamos con sólo tres posibles contratos en función de su objeto: 
- Obra

- Suministro

- Servicios

Así como las combinaciones de prestaciones correspondientes a distintos tipos, a los que la ley sigue denominando contratos mixtos (artículo 12) y para los que establece que se aplicarán las normas del tipo de contrato que tenga más importancia desde el punto de vista económico.

Se consideran contratos de obra los que tienen por objeto la realización de una obra o la ejecución de alguno de los trabajos enumerados en el Anexo I de la ley, o la realización por cualquier medio de una obra que responda a las necesidades especificadas por la entidad del sector público contratante. Además de estas prestaciones, el contrato podrá comprender, en su caso, la redacción del correspondiente proyecto. Por «obra» se entenderá el resultado de un conjunto de trabajos de construcción o de ingeniería civil, destinado a cumplir por sí mismo una función económica o técnica, que tenga por objeto un bien inmueble.

Son contratos de suministro los que tienen por objeto la adquisición, el arrendamiento financiero, o el arrendamiento, con o sin opción de compra, de productos o bienes muebles.

Por último, son contratos de servicios aquéllos cuyo objeto son prestaciones de hacer consistentes en el desarrollo de una actividad o dirigidas a la obtención de un resultado distinto de una obra o un suministro.

Hasta ahora hemos visto los distintos tipos de contratos clasificados en función de su objeto. Pero la ley (aunque su situación en el mismo capítulo que los anteriores no sea muy afortunada) crea una nueva fórmula de categorización de los contratos del sector público:

- Contratos sujetos a regulación armonizada

- Contratos no sujetos a regulación armonizada

Según la exposición de motivos de la ley, la categoría legal de «contratos sujetos a regulación armonizada», define los negocios que, por razón de la entidad contratante, de su tipo y de su cuantía, se encuentran sometidos a las directrices europeas. La positivación de esta categoría tiene por finalidad permitir la modulación de la aplicabilidad de las disposiciones comunitarias a los distintos contratos del sector público, restringiéndola, cuando así se estime 
conveniente, sólo a los casos estrictamente exigidos por ellas. Por exclusión, utilizándolo de forma negativa, el concepto también sirve para definir el conjunto de contratos respecto de los cuales el legislador nacional tiene plena libertad en cuanto a la configuración de su régimen jurídico.

El artículo 13 y siguientes determinan los contratos que se encuentran bajo esta consideración, dejando claro que el sometimiento a la regulación armonizada es una obligación de los entes que tengan el carácter de poder adjudicador, quedando por tanto, incluidas las fundaciones del sector público.

Centrándonos en los tres tipos contractuales que nos interesan, estarían sujetos a regulación armonizada los siguientes contratos:

- $\quad$ Obra: los de importe superior a 5.150.000€

- Suministro y servicios: los de importe superior a $206.000 €$.

Las cuantías expresadas son las vigentes para el año 2008 en virtud de lo dispuesto en la Orden EH A/ 3875/2007, de 27 de diciembre, y no coinciden con las cuantías expresadas en la redacción original de la Ley $30 / 2007$ ( $5.278 .000 €$ para contratos de obra y 211.000 para suministros y servicios).

Resulta obvio que el legislador es consciente de la pesada losa que supone el sometimiento de los contratos a las Directivas Comunitarias y del abuso que en muchas ocasiones se produce en el seno de los poderes adjudicadores acudiendo a la técnica de la división por lotes de prestaciones de determinados tipos de contratos que, sumados, superarían los límites cuantitativos establecidos. Por ello, en estos mismos artículos, intenta poner freno a tan extendida práctica regulando las posibilidades y consecuencias de la división por lotes; de esta manera establece que cuando el valor acumulado de los lotes en que se divida la obra, suministro o servicio iguale o supere las cantidades indicadas, se aplicarán las normas de regulación armonizada en la adjudicación de cada lote.

Por último, una breve alusión a otra importante novedad que constituyen los denominados contratos subvencionados. La ley establece que también están sujetos a regulación armonizada los contratos que sobrepasen unos determinados límites (artículo 17) realizados por cualquier persona física o jurídica, pública o privada que hayan sido subvencionados en más de un $50 \%$ de su importe por entidades que tengan la consideración de poder adjudicador. 


\section{DISPOSICIONES GENERALES SOBRE LA CONTRATACIÓN DEL SECTOR PÚBLICO}

Analizamos a continuación una serie de estipulaciones, principios y disposiciones (título I del libro I, título II del libro V y algunas disposiciones adicionales) de carácter general que afectan a la contratación de las entidades del sector público en general. Destacamos aquellas que pueden afectar al régimen de contratación de las fundaciones del sector público.

\section{Necesidad e idoneidad del contrato (artículo 22)}

Los entes, organismos y entidades del sector público no podrán celebrar otros contratos que aquéllos que sean necesarios para el cumplimiento y realización de sus fines institucionales. A tal efecto, la natural eza y extensión de las necesidades que pretenden cubrirse mediante el contrato proyectado, así como la idoneidad de su objeto y contenido para satisfacerlas, deben ser determinadas con precisión, dejando constancia de ello en la documentación preparatoria, antes de iniciar el procedimiento encaminado a su adjudicación.

\section{Plazo de duración de los contratos (artículo 23)}

Sin perjuicio de las normas especiales aplicables a determinados contratos, la duración de los contratos del sector público deberá establecerse teniendo en cuenta la naturaleza de las prestaciones, las características de su financiación y la necesidad de someter periódicamente a concurrencia la realización de las mismas.

El contrato podrá prever una o varias prórrogas siempre que sus características permanezcan inalterables durante el periodo de duración de éstas y que la concurrencia para su adjudicación haya sido realizada teniendo en cuenta la duración máxima del contrato, incluidos los periodos de prórroga. La prórroga se acordará por el órgano de contratación y será obligatoria para el empresario, salvo que el contrato expresamente prevea lo contrario, sin que pueda producirse por el consentimiento tácito de las partes.

Los contratos menores definidos en el artículo 122.3 no podrán tener una duración superior a un año ni ser objeto de prórroga.

\section{Libertad de pactos (artículo 25)}

En los contratos del sector público podrán incluirse cualesquiera pactos, cláusulas y condiciones, siempre que no sean contrarios al interés público, al ordenamiento jurídico y a los principios de buena administración. 
Sólo podrán fusionarse prestaciones correspondientes a diferentes contratos en un contrato mixto cuando esas prestaciones se encuentren directamente vinculadas entre sí y mantengan relaciones de complementariedad que exijan su consideración y tratamiento como una unidad funcional dirigida a la satisfacción de una determinada necesidad o a la consecución de un fin institucional propio del ente, organismo o entidad contratante.

\section{Contenido mínimo del contrato (artículo 26)}

Salvo que ya se encuentren recogidas en los pliegos, los contratos que celebren los entes, organismos y entidades del sector público deben incluir, necesariamente, las siguientes menciones:

a) La identificación de las partes.

b) La acreditación de la capacidad de los firmantes para suscribir el contrato.

c) Definición del objeto del contrato.

d) Referencia a la legislación aplicable al contrato.

e) La enumeración de los documentos que integran el contrato. Si así se expresa en el contrato, esta enumeración podrá estar jerarquizada, ordenándose según el orden de prioridad acordado por las partes, en cuyo supuesto, y salvo caso de error manifiesto, el orden pactado se utilizará para determinar la prevalencia respectiva, en caso de que existan contradicciones entre diversos documentos.

f) El precio cierto, o el modo de determinarlo.

g) La duración del contrato o las fechas estimadas para el comienzo de su ejecución y para su finalización, así como la de la prórroga o prórrogas, si estuviesen previstas.

h) Las condiciones de recepción, entrega o admisión de las prestaciones.

i) Las condiciones de pago.

j) Los supuestos en que procede la resolución.

k) El crédito presupuestario o el programa o rúbrica contable con cargo al que se abonará el precio, en su caso.

I) La extensión objetiva y temporal del deber de confidencialidad que, en su caso, se imponga al contratista.

El documento contractual no podrá incluir estipulaciones que establezcan derechos y obligaciones para las partes distintos de los previstos en los pliegos, concretados, en su caso, en la forma que resulte de la proposición del adjudicatario, o de los precisados en el acto de adjudicación del contrato de acuerdo con lo actuado en el procedimiento, de no existir aquéllos. 


\section{Perfección de los contratos (artículo 27)}

Los contratos de las Administraciones Públicas, en todo caso, y los contratos sujetos a regulación armonizada, incluidos los contratos subvencionados, se perfeccionan mediante su adjudicación definitiva, cualquiera que sea el procedimiento seguido para llegar a ella.

En este punto sí merece la pena detenerse, puesto que la perfección del contrato mediante su adjudicación lo encuadra como una característica propia de los contratos de las Administraciones Públicas. Este matiz es importante porque debemos entender que los contratos adjudicados por el resto de entidades del sector público, incluidas lógicamente las fundaciones, se perfeccionan siguiendo las reglas establecidas en derecho privado: según establece el artículo 1258 del Código Civil (al que remite el artículo 50 del Código de Comercio), "Ios con tratos se perfeccionan por el mero con sentimiento, y desde entonces obligan, no sólo al cumplimiento de lo expresamente pactado, sino también a todas las consecuencias que, según su naturaleza, sean conformes a la buena fe, al uso y a la ley".

Este artículo lo debemos ver en conjunto con el 28, que prohíbe los contratos verbales (salvo los que tengan carácter de emergencia). De la conjunción de ambos artículos podemos concluir que los contratos adjudicados por el resto de entidades del sector público se perfeccionan por la formalización y firma del contrato.

\section{Lugar de celebración del contrato (artículo 27)}

Salvo que se indique otra cosa en su clausulado, los contratos del sector público se entenderán celebrados en el lugar donde se encuentre la sede del órgano de contratación; precepto que resulta fundamental a la hora de determinar la jurisdicción competente en caso de conflicto en el desarrollo o interpretación del contrato.

\section{Remisión de información a efectos estadísticos y de fiscalización (arts. 29 y 30)}

Al no existir una mención expresa de la tipología de entidades a que se refiere, hemos de entender aplicable a las fundaciones lo dispuesto en estos dos artículos relativos a la remisión de información a los órganos de fiscalización, en el caso de las fundaciones del sector público andaluz a la Cámara de Cuentas, siempre que los contratos superen las siguientes cuantías: 
- Obras: más de 600.000

- Suministros: más de 450.000

- $\quad$ Servicios: más de 150.000

Para determinar los contratos que han de remitirse a la Junta Consultiva de Contratación Administrativa o al Registro de Contratos de la Comunidad Autónoma, la ley remite al desarrollo reglamentario.

\section{El recurso especial en materia de contratación (artículo 37 y siguientes)}

Este recurso supone otra de las grandes novedades de la Ley 30/2007. Se crea el recurso especial en materia de contratación, cuya interposición por parte de los perjudicados o afectados tendrá carácter obligatorio como trámite previo a la interposición del recurso contencioso administrativo.

De la redacción de este extenso artículo, que aunque no se diga expresamente, puede deducirse que se trata de una particularidad de las Administraciones Públicas, téngase en cuenta que tiene carácter obligatorio previo al contencioso administrativo y que, como ya ha quedado apuntado, la jurisdicción competente en la contratación de los entes del sector público que no son administración pública es la jurisdicción civil.

Por su parte, sí cabría la interposición de este recurso sea cual sea la entidad contratante cuando estemos hablando de contratos sujetos a regulación armonizada, como se desprende de lo dispuesto en el artículo 21.2 "in fine".

La solución que propone el artículo 39 de la ley para los entes, organismos y entidades del sector público que no tengan el carácter de Administraciones Públicas es una figura propia del derecho privado, el arbitraje, conforme a las disposiciones de la Ley 60/ 2003, de 23 de diciembre, de Arbitraje. Este tipo de entidades podrán remitir a arbitraje la solución de las diferencias que puedan surgir sobre los efectos, cumplimiento y extinción de los contratos que celebren. Nada dice sobre las divergencias en cuanto a la preparación y adjudicación.

\section{Registro de contratos del sector público (artículo 308 y siguientes)}

El Ministerio de Economía y H acienda creará y mantendrá un Registro de Contratos, en el que se inscribirán los datos básicos de los contratos adjudicados por las distintas Administraciones Públicas y demás entidades del sector público sujetos a esta Ley. El Registro de Contratos del Sector Público consti- 
tuye el sistema oficial central de información sobre la contratación pública en España y, como tal, el soporte para el conocimiento, análisise investigación de la contratación pública, para la estadística en materia de contratos públicos, para el cumplimiento de las obligaciones internacionales de España en materia de información sobre la contratación pública, para las comunicaciones de los datos sobre contratos a otros órganos de la Administración que estén legalmente previstas y, en general, para la difusión pública de dicha información, de conformidad con el principio de transparencia.

El Registro constituirá el instrumento de los poderes públicos para la revisión y mejora continuas de los procedimientos y prácticas de la contratación pública, el análisis de la calidad, fiabilidad y eficiencia de sus proveedores, y la supervisión de la competencia y transparencia en los mercados públicos.

Los órganos de contratación de todas las Administraciones públicas y demás entidades incluidas en el ámbito de aplicación de esta Ley comunicarán al Registro de Contratos del Sector Público, para su inscripción, los datos básicos de los contratos adjudicados, así como, en su caso, sus modificaciones, prórrogas, variaciones de plazos o de precio, su importe final y extinción. La ley remite al desarrollo reglamentario la determinación del contenido de dichas comunicaciones y el plazo para efectuarlas.

\section{Contratación con empresas de trabajo temporal (Disposición adicional quinta)}

Ha sido uno de los puntos más controvertidos en el proceso de elaboración y aprobación de la ley.

La prohibición recogida y sus excepciones afectan de lleno a las fundaciones del sector público:

No podrán celebrarse contratos de servicios con empresas de trabajo temporal salvo cuando se precise la puesta a disposición de personal con carácter eventual para la realización de encuestas, toma de datos y servicios análogos.

En estos contratos, vencido su plazo de duración, no podrá producirse la consolidación como personal del ente, organismo o entidad contratante de las personas que, procedentes de las citadas empresas, realicen los trabajos que constituyan su objeto, sin que sea de aplicación lo establecido en el artículo 7.2 de la Ley 14/ 1994, de 1 de junio, por la que se regulan las empresas de trabajo temporal. 
La duración de estos contratos en ningún caso podrá superar el plazo de seis meses, extinguiéndose a su vencimiento sin posibilidad de prórroga.

\section{Cómputo de plazos (Disposición adicional decimoquinta)}

Los plazos establecidos por días en esta Ley se entenderán referidos a días naturales, salvo que en la misma se indique expresamente que sólo deben computarse los días hábiles. No obstante, si el último día del plazo fuera inhábil, éste se entenderá prorrogado al primer día hábil siguiente.

\section{VII.PARTES EN EL CONTRATO}

Como en todo contrato y por la propia naturaleza de la institución, en los contratos del sector público hay dos partes, la parte contratante, que debe ser una entidad de las citadas en el artículo 3, y la parte contratada, el empresario sea persona física o jurídica, español o extranjero que tenga plena capacidad de obrar, no esté incurso en prohibición de contratar y acredite su solvencia económica, financiera y técnica o profesional (artículo 43).

\section{Parte contratante}

La competencia para contratar, por tanto, el órgano de contratación en las fundaciones del sector público, es el patronato, órgano supremo y sobre el que recae la responsabilidad legal de “... cumplir los fines fundacionales y administrar con diligencia los bienes y derechos que integran el patrimonio de la fundación, manteniendo el rendimiento y utilidad de los mismos" (artículo 15 de la ley 10/ 2005). Pero la ley permite delegar o desconcentrar esa competencia, mediante la técnica de la delegación, en el caso que se trate de órganos administrativos, y mediante el otorgamiento de poderes, cuando se trate de órganos societarios y fundaciones.

De hecho, el otorgamiento de poderes a favor del presidente o más comúnmente del gerente o director, es una práctica muy habitual. Ese otorgamiento debe hacerse por acuerdo del patronato válidamente constituido y por elevación a documento público del acuerdo que se adopte.

La ley distingue entre el órgano de contratación, que es el órgano o persona con capacidad para obligarse en nombre de la fundación, y el responsable del contrato, que es una persona física o jurídica, vinculada al ente contratante 0 ajena a él, designada por el órgano de contratación, a quien co- 
rresponde supervisar su ejecución y adoptar las cesiones y dictar instrucciones que aseguren la correcta realización de la prestación pactada. Se entiende que se debe designar un responsable, si lo hubiere, por cada contrato que se celebre; si su competencia se extendiera a un número indeterminado de contratos, estaríamos ante una subdelegación o ante el otorgamiento de un poder general.

\section{Parte contratada}

Se entiende aplicable a las fundaciones del sector público andaluz todo lo dispuesto en el capítulo II del título II, relativo a la aptitud del contratante para contratar con el sector público: condiciones de aptitud (artículo 43), empresas comunitarias (artículo 44), condiciones especiales de compatibilidad ( artículo 45), normas especiales sobre capacidad (artículos 46 a 48), prohibiciones de contratar ( artículos 49 y 50), condiciones de solvencia (artículos 51 a 53) , así como la sección 2, íntegra, en la que se regulan los medios para acreditar la aptitud para contratar.

Sin embargo, la subsección 5a (artículos 54 a 60) reguladora de la clasificación de las empresas, se ciñe al ámbito de los contratos de las Administraciones Públicas, ya que el primer artículo dedicado al tema (artículo 54), abre diciendo "Para contratar con las Administraciones Públicas la ejecución de contratos de (... ) será requisito indispensable que el empresario se en cuen tre debidamente clasificado".

La exigencia de clasificación es potestativa para el resto de entidades del sector público y pueden exigirla si lo estiman oportuno para definir las condiciones de solvencia requeridas (artículo 54.5).

\section{VIII.OBJETO, PRECIO, CUANTÍA Y GARANTÍAS DEL CONTRATO}

\section{Normas generales}

Todas las normas generales relativas a objeto, precio y cuantía de los contratos (capítulo I del título III), son de aplicación a todo el sector público. De esta forma, la necesidad de objeto determinado y precio cierto expresado en euros, son requisitos esenciales de los contratos.

Entendemos que el hecho de que el artículo 75, apartado 7, prohíba expresamente el pago aplazado del precio de los contratos de las Administra- 
ciones Públicas, abre tal posibilidad a los contratos celebrados por el resto de entidades.

Es importante resaltar en este punto la norma contenida en el artículo 76, de enorme importancia práctica, pues establece que a los efectos previstos en la ley, el valor estimado de los contratos vendrá determinado por el importe total, sin incluir el Impuesto sobre el Valor Añadido.

\section{Revisión de precios}

El propio enunciado del capítulo contiene que la regulación de los mecanismos de revisión de precios tienen como destinatarios exclusivos los contratos de las Administraciones Públicas, por lo que cabe entender que la libertad de pacto debe ser el principio que rija los sistemas de revisión aplicables a los contratos del resto de entidades del sector público, que en cualquier caso deben quedar establecidos en el pliego de cláusulas administrativas particulares o en el propio texto del contrato.

\section{Garantías}

El asunto relativo a las garantías exigibles en la contratación del sector público está sometido a doble regulación.

El capítulo I (artículo 83 y siguientes) establece las normas aplicablesa las garantías a prestar en contratos celebrados con las Administraciones Públicas, regulación extensa y pormenorizada.

Por su parte, a las garantías de los contratos celebrados con el resto de entidades del sector público se dedica un único artículo (artículo 92), que establece, al igual que en la exigibilidad de clasificación, la garantía como algo potestativo. Se trata de una posibilidad o un mecanismo del que pueden disponer los órganos de contratación para responder del mantenimiento de las ofertas ( garantía provisional) o para asegurar la correcta ejecución de la prestación derivada del contrato (garantía definitiva).

\section{PREPARACIÓN DE LOS CONTRATOS}

El régimen de preparación de los contratos contenido en el libro II de la ley también está sometido a doble regulación: el título I (artículos 93 a 120) regula pormenorizadamente la preparación de los contratos de las Adminis- 
traciones Públicas, y el capítulo único del título II, establece las reglas aplicables a la preparación de los contratos celebrados por poderes adjudicadores que no tengan el carácter de Administraciones Públicas y de contratos subvencionados. Es en este apartado en el que nos detenemos para su análisis por ser el régimen de preparación de los contratos de las fundaciones del sector público.

La ley establece dos tipos de regímenes aplicables en función de la cuantía y objeto del contrato de que se trate: el primero (artículo 121.1) aplicable a los contratos celebrados por poderes adjudicadores que no tengan el carácter de Administraciones Públicas y que, además, reúnan alguna o algunas de las siguientes peculiaridades:

- Que estén sujetos a regulación armonizada.

- Que sean contratos de servicios comprendidos en alguna de las categorías expresadas a continuación y ( 17 a 27 del Anexo II) de cuantía igual o superior a 211.000 euros:

Servicios de hostelería y restaurante.

Servicios de transporte por ferrocarril.

Servicios de transporte fluvial y marítimo.

Servicios de transportes complementarios y auxiliares.

Servicios jurídicos.

Servicios de colocación y suministro de personal.

Servicios de investigación y seguridad, excepto servicios de furgones blindados.

Servicios de educación y formación profesional.

Servicios sociales y de salud.

Servicios de esparcimiento, culturales y deportivos.

Otros servicios.

- Que se trate de contratos subvencionados.

Para estos supuestos determina que deberán observarse una serie de reglas que en principio estaban reservadas al ámbito de las Administraciones Públicas, se trata de las reglas establecidas en el artículo 101 para la definición y establecimiento de prescripciones técnicas, siendo igualmente de aplicación lo previsto en los artículos 102 a 104.

Por otro lado, el artículo 121 abre la puerta a que el resto de entidades del sector público utilicen la modalidad de contratación urgente, aunque no 
queda claro si esta posibilidad se ciñe a la totalidad de los contratos o sólo a los que reúnan las características expresadas anteriormente.

En contratos distintos a los mencionados en el apartado anterior de cuantía superior a 50.000 euros, los poderes adjudicadores que no tengan el carácter de Administraciones Públicas deberán elaborar un pliego, en el que se establezcan las siguientes cuestiones:

- Las características básicas del contrato

- El régimen de admisión de variantes

- Las modalidades de recepción de las ofertas

- Los criterios de adjudicación

- Las garantías que deberán constituir, en su caso, los licitadores o el adjudicatario

También dispone que será de aplicación a estos contratos lo dispuesto en el artículo 104, relativo a la información a facilitar a los licitadores sobre condiciones de subrogación en contratos de trabajo.

Se cierra el artículo estableciendo que estos pliegos serán parte integrante del contrato.

Quedan sin requerimientos específicos la preparación de los contratos de cuantía inferior a $50.000 €$, cuestión perfectamente entendible en el caso de contratos de obra porque coincide la cuantía con la del contrato menor. Pero en el caso del resto de contratos, la cuantía para ser considerados contratos menores es de $18.000 €$. Cabe, pues, plantearse qué ocurre con los contratos de servicios o de suministros que superen esta cuantía, ya que en principio deben sacarse a pública concurrencia y sería deseable la existencia de un pliego o al menos el establecimiento claro de las condiciones de ejecución del contrato.

\section{ADJUDICACIÓN DE LOSCONTRATOS}

Es en el libro tercero dedicado a la selección del contratista y adjudicación de los contratos donde la técnica de legislación "a la carta" alcanza su máxima expresión, ya que el texto regula por separado la adjudicación de los contratos de los tres tipos de entes del sector público:

Capítulo I. Adjudicación de los contratos de las Administraciones Públicas 
Capítulo II. Adjudicación de otros contratos del sector público.

Sección 1a. Normas aplicables por los poderes adjudicadores que no tengan el carácter de Administraciones Públicas.

Sección 2a. Normas aplicables por otros entes, entidades y organismos del sector público.

Sección 3ạ. N ormas aplicables a la adjudicación de los contratos subvencionados.

Nos centramos, pues, en el análisis de la sección 1a del capítulo II del Libro III, donde se encuentran las fundaciones del sector público andaluz.

La sección segunda se compone de tres artículos (173 a 175), el primero de introducción y dos de regulación:

En primer lugar, se regulan los contratos de los poderes adjudicadores que no tengan el carácter de Administraciones Públicas cuando por sus características se trate de contratos sujetos a regulación armonizada. Para estos casos la ley establece que son de aplicación las normas del capítulo anterior con una serie de excepciones y adaptaciones:

a) "No serán de aplicación las normas establecidas en el segundo párrafo del apartado 2 del artículo 134 sobre in terven ción del comité de expertos para la valoración de criterios subjetivos, en los apartados 1 y 2 del artículo 136 sobre criterios para apreciar el carácter anormal o desproporcionado de las ofertas, en el artículo 140 sobre formalización de los contratos, en e artículo 144 sobre examen de las proposiciones y propuesta de adjudicación, y en el artículo 156 sobre los supuestos en que es posible acudir a un procedimiento negociado para adjudicar contratos de gestión de servicios públicos.

b) No será preciso publicar las licitaciones y adjudicaciones en los diarios oficiales nacionales a que se refieren el párrafo primero del apartado 1 del artículo 126 y el párrafo primero del apartado 2 de artículo 138, en tendién dose quese satisfacee principio de publicidad me diante la publicación efectuada en el «Diario O ficial de la Unión Europea» y la inserción de la correspondiente información en la plataforma de contratación a que se refiere el artículo 309 o en el sistema equivalente gestionado por la Administración Pública de la que dependa la entidad contratante, sin perjuicio de la utilización de medios adicionales con carácter voluntario".

El artículo 175 regula someramente la adjudicación de los contratos de las entidades del sector público que no tengan el carácter de Administraciones Públicas y que no estén sujetos a regulación armonizada, es decir, la inmensa mayoría de contratos de las fundaciones del sector público. Se trata de uno de los artículos más importantes y sustanciosos de la ley en lo que a entes 
instrumentales se refiere. Lo reproducimos en su tenor literal para proceder después a su análisis pormenorizado:

“Artículo 175. Adjudicación de los con tratos que no estén sujetos a regulación armonizada. En la adjudicación de contratos no sujetos a regulación armonizada serán de aplicación las siguientes disposiciones:

a) La adjudicación estará sometida, en todo caso, a los principios de publicidad, concurrencia, transparencia, confidencialidad, igualdad y no discriminación.

b) L os órganos competentes de las entidades a que se refiere esta sección aprobarán unas instrucciones, de obligado cumplimiento en el ámbito interno de las mismas, en las que se re gulen los procedimientos de contratación de forma que quede garantizada la efectividad de los principios en unciados en la letra anterior y que el contrato es adjudicado a quien pre sente la oferta económicamente más ventajosa. Estas instrucciones deben ponerse a disposición de todos los interesados en participar en los procedimientos de adjudicación de contratos regulados por ellas, y publicarse en el perfil de contratante de la entidad. En el ámbito del sector público estatal, la a probación de las instrucciones requerirá el informe previo dela A bogacía del Estado.

c) Se entenderán cumplidas las exigencias derivadas del principio de publicidad con la inserción de la información relativa a la licitación de los contratos cuyo importe supere los 50.000 euros en el perfil del contratante de la entidad, sin perjuicio de quelas instrucciones internas de contratación puedan arbitrar otras modalidades, alternativas 0 adicionales, de difusión."

\section{Los principios que rigen la adjudicación}

La adjudicación de los contratos de las entidades del sector público que no tengan el carácter de Administraciones Públicas, está sometida a una serie de principios rectores de obligado cumplimiento. La ley en esto es rigurosa, pues utiliza el verbo "someter". No se trata de principios inspiradores sino de auténticas normas jurídicas cuya efectividad debe quedar garantizada y patente en las normas de contratación de las entidades. Los principios rectores son:

- Publicidad.

- Concurrencia.

- Transparencia.

- Confidencialidad.

- Igualdad.

- No discriminación.

La lista de principios aplicables es considerablemente más amplia que en la legislación de contratos anterior. Recordemos que la disposición adicional sexta establecía que las sociedades mercantiles y las fundaciones del sector público se ajustarían en su actividad contractual a los principios de publicidad y concurrencia. 
Es importante destacar que la nueva legislación no admite excepciones a la aplicación de los principios de contratación. La salvedad prevista en el texto refundido, "salvo que la naturaleza de la operación a realizar sea incompatible con estos principios", que por su indefinición ha constituido una fuente inagotable de excepciones, ha desaparecido del texto, lo que convierte a la aplicabilidad efectiva de los principios expresados en algo inexcusable.

Por su parte, la legislación estatal de fundaciones (ley 50/ 2002), artículo 46.5 , establece que la contratación de las fundaciones del sector público estatal se ajustará a los principios de publicidad, concurrencia y objetividad.

La nueva ley amplía, por tanto, los principios rectores de la contratación de las fundaciones del sector público añadiendo cuatro más, cuya trascendencia vamos a ver por separado:

\section{- Principios de publicidad y concurrencia}

Son los dos grandes clásicos de la contratación administrativa. La concurrencia es una consecuencia de la adecuada difusión publicitaria. Por pura lógica, mientras más difusión se dé a una convocatoria más empresas interesadas se van a dar por enteradas y más licitadores van a concurrir a la misma.

Otro elemento que puede favorecer la efectividad del principio de concurrencia, es otorgar un plazo de presentación de solicitudes que sea razonable y adecuado para que las empresas interesadas puedan preparar una oferta de calidad y ajustada a las exigencias del concurso.

Pero también la ley entiende que en muchas ocasiones el gasto de difusión de los anuncios puede ser excesivo, una partida importante del contrato, y considera que el principio de publicidad queda suficientemente garantizado con la inserción de la información relativa a la licitación de los contratos de importe superior a 50.000 en el perfil de contratante de la entidad, cuestión a la que nos referiremos más adelante. Esta exigencia constituye un mínimo, ya que la propia ley permite a las entidades del sector público arbitrar otras medidas alternativas o adicionales de difusión con carácter permanente o cuando lo estime oportuno en virtud de determinados contratos.

Esto va a suponer un cambio importante en el modo de actuar de las empresas interesadas en trabajar con el sector público, ya que va a implicar una actitud más activa y estar más pendiente de las páginas web de las entidades 
con las que trabajan, porque la información (salvo importantes excepciones) no les va a llegar ya servida en la prensa diaria ni en los boletines oficiales.

- Principio de transparencia

El principio de transparencia es uno de los principios básicos generales del régimen jurídico de las Administraciones Públicas y de esa manera aparece expresado en el Artículo 3.5. de la Ley 30 / 1992, de 26 de noviembre (redactado según Ley 4/ 1999, de 13 de enero) , que establece que en sus relaciones con los ciudadanos las Administraciones Públicas actúan de conformidad con los principios de transparencia y de participación.

La nueva ley de contratos hace extensible la obligatoriedad de la observancia de este principio a las entidades del sector público en lo que a su actividad contractual se refiere.

Entendemos que la aplicación del principio de transparencia tiene una enorme trascendencia práctica, fundamentalmente en el procedimiento de adjudicación, que obligará a poner en conocimiento de los licitadores cada uno de los pasos que se vayan dando y el porqué de cada una de las decisiones que se adopten. De la legislación anterior se podía deducir que una vez cerrado el plazo de presentación de ofertas y habiéndose dado debido cumplimiento a la publicidad y concurrencia, el órgano de contratación no tenía más que comunicar el resultado del proceso de adjudicación sin más explicaciones. La exigencia legal expresa de transparencia va a requerir que se hagan público, entre otros, los siguientes extremos.

- Relación de ofertas presentadas.

- Relación de ofertas admitidas y rechazadas acompañadas de las causas de inadmisión.

- Detalles sobre la composición de la mesa y del órgano de contratación

- Situación en la que se encuentra el procedimiento.

- Empresa adjudicataria acompañada de los motivos o criterios para la adjudicación.

- Relación de empresas no adjudicatarias.

- Principio de confidencialidad

Es un principio inspirador de la actividad de las entidades del sector público en general, que va a obligar a no transferir datos sobre el contenido de 
las ofertas ni datos de carácter personal de los licitadores, más allá de los exigidos por el principio de transparencia.

Podríamos considerar la confidencialidad como una autolimitación del principio de transparencia, en virtud de la cual deben hacerse públicos los datos, trámites y decisiones que el sentido común y la práctica jurídica y mercantil entiendan como publicables.

Entre otras acciones, el principio de confidencialidad nos va a obligar a marcar claramente un plazo para retirar la documentación correspondiente a las ofertas que no hayan resultado adjudicatarias; si en el plazo marcado quedara alguna sin retirar debe procederse a su destrucción bajo certificación.

El artículo 124 de la propia ley fija el alcance de este principio en relación a la adjudicación de los contratos de las Administraciones Públicas y establece que sin perjuicio de las disposiciones de la presente ley relativas a la publicidad de la adjudicación y a la información que debe darse a los candidatos y a los licitadores, los órganos de contratación no podrán divulgar la información facilitada por los empresarios que éstos hayan designado como confidencial. Este carácter afecta, en particular, a los secretos técnicos o comerciales y a los aspectos confidenciales de las ofertas.

Pero también el principio de confidencialidad implica al contratista , ya que éste deberá respetar el carácter confidencial de aquella información a la que tenga acceso con ocasión de la ejecución del contrato a la que se le hubiese dado el referido carácter en los pliegos o en el contrato, o que por su propia naturaleza deba ser tratada como tal. Este deber se mantendrá durante un plazo de cinco años desde el conocimiento de esa información, salvo que los pliegos o el contrato establezcan un plazo mayor.

- Principio de igualdad y no discriminación.

Se trata de un principio de rango constitucional traído al ámbito de la contratación administrativa. La igualdad y no discriminación debe ser una consecuencia de la correcta aplicación del resto de principios consagrados en este artículo, toda vez que la publicidad y concurrencia garantizan la igualdad entre todas las empresas y profesionales del sector. El principio de transparencia garantiza la aplicación del principio de igualdad se trata de una ventana abierta a la que cualquiera se puede asomar para verificar el trato igualitario de todas las ofertas. 
Pero el principio de igualdad y la no discriminación tienen también una vertiente objetiva y de plena aplicación práctica, ya que la no discriminación implica el "no favoritismo"; no hay ninguna razón que justifique que una oferta parta con ventaja respecto a las demás, ni el hecho de que el licitador haya trabajado ya con la entidad y "sabemos que funciona", ni ninguna otra de similares características y demasiado recurrentes.

\section{El procedimiento de contratación}

El apartado b) del artículo 175 regula el procedimiento de contratación de los poderes adjudicadores que no tengan el carácter de Administraciones Públicas a través del establecimiento de una serie de normas generales que vamos a ver por separado:

- Instrucciones reguladoras de los procedimientos de contratación.

La ley establece que este tipo de entidades deben contar con una normativa interna reguladora de los procedimientos de contratación. Para la validez de estas normas la ley exige el cumplimiento de cuatro requisitos:

1 Q ue sean aprobadas por el órgano competente, esto es, por el órgano de contratación de cada entidad. Pero debemos entender que, dada la trascendencia de esta normativa interna, ha de ser el órgano que tenga la potestad original y no el que la ostente por delegación o por otorgamiento de facultades. Así, en las fundaciones del sector público andaluz entendemos que deben ser aprobadas por el correspondiente patronato.

2ㅇ Que las instrucciones de contratación garanticen la efectividad de los principios enumerados en el apartado anterior, de manera que el contrato sea adjudicado a la oferta económicamente más ventajosa ( a este importante requisito le dedicamos el apartado siguiente del presente capítulo).

3o Que las instrucciones se pongan a disposición de los interesados en participar en los procedimientos de adjudicación de contratos regulados por ellas y se publiquen en el perfil de contratante de la entidad. Cuestión ésta que no requiere más comentarios.

40 En el ámbito del sector público estatal, la aprobación de las instrucciones requerirá el informe previo de la Abogacía del Estado. Al no decirlo expresamente, hemos de entender, en aplicación del artículo 83.1 de la Ley 30/ 1992, que se trata de un informe no vinculante, aunque también se hace difícil pensar que el patronato de una fun- 
dación pública pueda aprobar unas instrucciones de contratación que cuentan con un informe negativo de la Abogacía del Estado. Sería razonable pensar que, o bien en el desarrollo reglamentario o en la normativa autonómica que se dicte en aplicación de la normativa estatal, se establezca algún órgano de fiscalización y vigilancia que asuma la función de informar las instrucciones reguladoras de los procedimientos de contratación de las fundaciones del sector público andaluz.

La existencia de esta normativa reguladora del procedimiento de contratación no debe suponer una novedad para los entes instrumentales de la administración autonómica andaluza puesto que, como vimos en el capítulo segundo de este texto, la Instrucción 3/ 2000 de la Intervención General daba por sentado que las empresas de la Junta de Andalucía debían tener establecido y aprobado un protocolo que regulase las competencias y procedimientos de contratación.

\section{La garantía de efectividad de los principios de contratación}

La ley exige que las instrucciones de contratación garanticen dos cuestiones: por un lado, la efectiva aplicación de los principios de publicidad, concurrencia, transparencia, confidencialidad, igualdad y no discriminación y, por otro, que establezca un mecanismo que garantice que los contratos van a ser adjudicados a los que planteen la oferta económicamente más ventajosa.

Se trata de dos cuestiones que quedan superadas con creces en la regulación de la adjudicación de los contratos de las Administraciones Públicas, regulados en el capítulo primero de este libro III. Y si en este capítulo se establecen los mecanismos que tienden a garantizar ambas cuestiones, estimamos que el resto de entidades del sector público deben encontrar en el referido capítulo I una fuente de inspiración clara e inequívoca para redactar sus instrucciones de contratación.

La ley establece dos tipos de procedimientos de adjudicación:

- Procedimientos ordinarios: abierto y restringido.

- Procedimientos especiales o excepcionales: negociado y diálogo competitivo.

Pero ¿cuáles deben ser los procedimientos utilizables por las fundaciones del sector público? La ley no lo dice expresamente en ningún artículo pero sí podría deducirse el siguiente panorama: 
El artículo 175. c) obliga a los poderes adjudicadores que no tengan la consideración de Administraciones Públicas a publicar en el perfil de contratante las licitaciones cuyo importe supere los $50.000 €$, lo que significaría recurrir a alguno de los procedimientos que implican publicidad: el procedimiento abierto, como procedimiento base, y el negociado con publicidad, utilizable sólo en ocasiones muy concretas.

Pero ¿qué ocurriría con los contratos cuyo importe se encuentra por debajo de esa cifra? ¿H abría que entender que son susceptibles de adjudicarse por contratación directa?

En principio son susceptibles de adjudicarse por contratación directa los denominados contratos menores, pero éste por su ubicación sistemática (artículo 122) parece ser un concepto restringido al ámbito de las Administraciones Públicas (capítulo I, título I del Libro III denominado "Adjudicación de los contratos de las Administraciones Públicas"). Por tanto, cabría deducir que al no mencionar ningún procedimiento concreto aplicable a los contratos de cuantía inferior a $50.000 €$, que las fundaciones del sector público tienen libertad para regular su adjudicación en su normativa interna reguladora de los procedimientos de contratación.

Y, con el fin de restringir la utilización del mecanismo de adjudicación directa, sería recomendable que esas normas internas se hiciesen eco del concepto de contrato menor (regulado en la ley para las Administraciones Públicas, pero no proscrita su utilización por el resto de entidades del sector público) en la misma cuantía que establece el artículo 122 ( $50.000 €$ para los contratos de obras y $18.000 €$ para los de servicios y suministros).

Con esta premisa el contrato de obras no tendría problemas, ya que la cuantía máxima para ser considerado contrato menor y la mínima para determinar la obligatoriedad de su publicación coinciden, por lo que estaríamos ante el supuesto de adjudicación directa de los contratos inferiores a $50.000 €$ y por procedimiento abierto, para los que superen esa cuantía.

Sin embargo, no se puede hacer tal simplificación con los contratos de servicios y de suministro. Como hemos visto, la ley obliga a publicar los contratos de importe superior a $50.000 € y$, por otro lado, se consideran menores los contratos de cuantía inferior a $18.000 €$. Nos encontraríamos con un segmento carente de regulación ( $>18.000 € y<50.000 €$ ). Consideramos que los contratos del referido importe deben adjudicarse por el procedimiento restringido, es decir, la petición expresa de al menos tres ofertas que garanticen la adjudicación a aquélla que resulte económicamente más ventajosa. 
Por tanto, los procedimientos de adjudicación propios de las fundaciones del sector público andaluz serían cuatro: tres de carácter general: adjudicación directa, procedimiento restringido y procedimiento abierto, y uno excepcional y tasado, el procedimiento negociado con publicidad.

a) Adjudicación directa:

Los contratos menores podrán adjudicarse directamente a cualquier empresario con capacidad de obrar y que cuente con la habilitación profesional necesaria para realizar la prestación, cumpliendo con las normas establecidas en el artículo 95.

b) Procedimiento restringido:

En el procedimiento restringido sólo podrán presentar proposiciones aquellos empresarios que, a su solicitud y en atención a su solvencia, sean seleccionados por el órgano de contratación. En este procedimiento estará prohibida toda negociación de los términos del contrato con los solicitantes 0 candidatos.

En el supuesto de utilización de este procedimiento, la efectiva aplicación de los principios de contratación exigiría el establecimiento claro y con carácter previo al anuncio de licitación de los criterios objetivos de solvencia con arreglo a los cuales serán elegidos los candidatos que hayan sido invitados a presentar proposiciones.

c) Procedimiento abierto

En el procedimiento abierto todo empresario interesado podrá presentar una proposición, quedando excluida toda negociación de los términos del contrato con los licitadores. Es el sistema natural y de más deseable utilización.

d) Procedimiento negociado

En el procedimiento negociado la adjudicación recaerá en el licitador justificadamente elegido por el órgano de contratación, tras efectuar consultas con diversos candidatos y negociar las condiciones del contrato con uno o varios de ellos. Se trata de un procedimiento excepcional, pues sólo cabe utilizarlo en una serie de supuestos establecidos por la ley (ver artículos 153 y siguientes). 
Todo lo expuesto acerca de los procedimientos de adjudicación de las fundaciones del sector público se puede resumir en el siguiente cuadro (las cifras expresan el importe de licitación de los contratos):

\begin{tabular}{|l|c|c|c|c|}
\hline & $\begin{array}{c}\text { ADJUDICACIÓN } \\
\text { DIRECTA }\end{array}$ & $\begin{array}{c}\text { CONCURSO } \\
\text { RESTRINGIDO }\end{array}$ & $\begin{array}{c}\text { CONCURSO } \\
\text { ABIERTO }\end{array}$ & $\begin{array}{c}\text { CONTRATOS } \\
\text { SUJETOSA } \\
\text { REGULACIÓN } \\
\text { ARMONIZADA }\end{array}$ \\
\hline OBRAS & Menos de & -- & $\begin{array}{c}\text { Más de } 50.000 € \text { Menos } \\
\text { de } 5.150 .000 €\end{array}$ & $\begin{array}{c}\text { Más de } \\
5.150 .000 €\end{array}$ \\
\hline $\begin{array}{l}\text { SUMINISTROS } \\
\text { Y SERVICIOS }\end{array}$ & $\begin{array}{c}\text { Menos de } \\
18.000 €\end{array}$ & Más de $18.000 €$ & Más de $50.000 €$ & $\begin{array}{c}\text { Más de } \\
\text { Menos de } 50.000 €\end{array}$ \\
\hline
\end{tabular}

\section{Sobre la forma de adjudicación}

La forma de adjudicar los contratos supone otra de las grandes novedades de la ley, ya que ha desaparecido la clásica distinción del artículo 74 del Texto Refundido, que distinguía entre la forma de concurso y la subasta.

La nueva ley establece que el contrato se adjudicará a la oferta "económicamente más ventajosa" y deja meridianamente claro que no se trata de adjudicar a la oferta cuyo precio sea el más bajo, sino aquélla que en su conjunto resulte más apropiada. Para precisar aún más, el artículo 134 establece una serie de criterios para la valoración de las proposiciones:

- Calidad

- Precio

- Plazo de ejecución o entrega de la prestación

- La rentabilidad

- El valor técnico

- Las características estéticas o funcionales

- La disponibilidad y coste de los repuestos

- El mantenimiento y la asistencia técnica

- El servicio postventa.

- Características medioambientales.

- Características vinculadas con la satisfacción de exigencias sociales que respondan a necesidades propias de las categorías de población especialmente desfavorecidas a las que pertenezcan los usuarios o beneficiarios de las prestaciones a contratar. 
Sólo en el caso de que se utilice un único criterio de adjudicación, éste será necesariamente el del precio más bajo.

En aplicación del principio de transparencia y con el fin de garantizar el principio de igualdad, es deseable que los órganos de contratación de las fundaciones del sector público detallen en el anuncio, en los pliegos o en el documento descriptivo, los criterios que han de servir de base para la adjudicación. Para reducir al mínimo la arbitrariedad en la adjudicación, es igualmente deseable que los criterios estén debidamente ponderados y que puedan valorarse mediante cifras o porcentajes obtenidos a través de la mera aplicación de fórmulas establecidas en el pliego. De esta forma la oferta económicamente más ventajosa será aquella que consiga una mayor puntuación resultante de la suma de los criterios.

La disposición adicional sexta establece una serie de medidas de carácter social que en caso de igualdad con las ofertas económicamente más ventajosas deben ser tenidas en cuenta en la adjudicación:

Los órganos de contratación podrán señalar en los pliegos la preferencia en la adjudicación de los contratos para las proposiciones presentadas por aquellas empresas públicas o privadas que, en el momento de acreditar su solvencia técnica, tengan en su plantilla un número de trabajadores con discapacidad superior al 2 por ciento, siempre que dichas proposiciones igualen en sus términos a las más ventajosas desde el punto de vista de los criterios que sirvan de base para la adjudicación.

I gualmente podrá establecerse la preferencia en la adjudicación de contratos para las proposiciones presentadas por aquellas empresas dedicadas específicamente a la promoción e inserción laboral de personas en situación de exclusión social, reguladas en la Disposición Adicional Novena de la Ley 12/ 2001, de 9 de julio, de medidas urgentes de reforma del mercado de trabajo para el incremento del empleo y la mejora de su calidad, valorándose el compromiso formal del licitador de contratar no menos del 30 por ciento de sus puestos de trabajo con personas pertenecientes a los siguientes colectivos, cuya situación será acreditada por los servicios sociales públicos competentes:

a) Perceptores de rentas mínimas de inserción, o cualquier otra prestación de igual o similar naturaleza, según la denominación adoptada en cada Comunidad Autónoma. 
b) Personas que no puedan acceder a las prestaciones a las que se hace referencia en el párrafo anterior, por falta del período exigido de residencia o empadronamiento, o para la constitución de la unidad perceptora, o por haber agotado el período máximo de percepción legalmente establecido.

c) Jóvenes mayores de dieciocho años y menores de treinta, procedentes de instituciones de protección de menores.

d) Personas con problemas de drogadicción o alcoholismo que se encuentren en procesos de rehabilitación o reinserción social.

e) Internos de centros penitenciarios cuya situación penitenciaria les permita acceder a un empleo, así como liberados condicionales y ex reclusos.

f) Personas con discapacidad.

En la misma forma y condiciones podrá establecerse tal preferencia en la adjudicación de los contratos relativos a prestaciones de carácter social o asistencial para las proposiciones presentadas por entidades sin ánimo de lucro, con personalidad jurídica, siempre que su finalidad o actividad tenga relación directa con el objeto del contrato, según resulte de sus respectivos estatutos o reglas fundacionales y figuren inscritas en el correspondiente registro oficial. En este supuesto el órgano de contratación podrá requerir de estas entidades la presentación del detalle relativo a la descomposición del precio ofertado en función de sus costes.

Los órganos de contratación podrán señalar en los pliegos de cláusulas administrativas particulares la preferencia en la adjudicación de los contratos que tengan como objeto productos en los que exista alternativa de comercio justo para las proposiciones presentadas por aquellas entidades reconocidas como Organizaciones de Comercio Justo, siempre que dichas proposiciones igualen en sus términos a las más ventajosas desde el punto de vista de los criterios que sirvan de base para la adjudicación.

Por último, decir que la ley distingue dos momentos de la adjudicación: La adjudicación provisional, que deberá ser acordada por el órgano de contratación en resolución motivada que deberá notificarse a los licitadores y publicada en el perfil del contratante, y la adjudicación definitiva, que se producirá cuando el adjudicatario haya presentado la documentación justificativa de hallarse al corriente de sus obligaciones tributarias y con la Seguridad Social y cualesquiera otros documentos que le reclame el órgano de contratación. La adjudicación definitiva también debe ser notificada y publicada. 


\section{Plazos}

El estricto cumplimiento de los plazos constituye uno de los elementos más característicos y significativos de la contratación administrativa. Su observancia implica tanto a la parte contratante (el sector público) como a la parte contratada (los licitadores).

Los plazos que establece el Libro III están contemplados como plazos mínimos y son vinculantes para las Administraciones Públicas y no para el resto de entidades del sector público, para las cuales puede servir el criterio general del artículo 127 que establece que los órganos de contratación fijarán los plazos de recepción de las ofertas y solicitudes de participación teniendo en cuenta el tiempo que razonablemente pueda ser necesario para preparar aquéllas, atendida la complejidad del contrato.

No obstante lo dicho, es recomendable que las fundaciones del sector público no pierdan de vista estos plazos de publicación, presentación de ofertas, de preadjudicación, etc. establecidos para las Administraciones Públicas, ya que pueden perfectamente servir como criterio para la fijación de plazos en sus correspondientes instrucciones de contratación.

\section{Racionalización técnica de la contratación}

Bajo este epígrafe se encuentran una serie de instrumentos tendentes a racionalizar y ordenar la adjudicación de los contratos públicos: acuerdos marco, sistemas dinámicos de contratación y centrales de contratación.

Según establecen los artículos 178 y 179, este título únicamente será de aplicación a las Administraciones Públicas y al resto de entidades del sector público sólo para la adjudicación de contratos sujetos a regulación armonizada.

\section{EL PERFIL DE CONTRATANTE}

Constituye el sistema de difusión y publicidad de las convocatorias de licitaciones y contrataciones de las entidades del sector público. La ley se hace eco de una realidad latente: Internet se ha convertido en el sistema de difusión más rápido, fiable, accesible y económico de cuantos existen. Es un sistema al alcance de todos, accesible en cualquier momento para los gestores de las entidades del sector público y para los particulares y que, además, garantiza la máxima difusión, por encima de boletines oficiales y de periódicos de 
cualquier ámbito. Como dice la propia ley, el perfil de contratante tiene como finalidad asegurar la transparencia y acceso público a la información relativa a la actividad contractual del sector público. No obstante, en muchas ocasiones y bajo un importante número de supuestos descritos en la ley, se mantiene la obligatoriedad de utilización de boletines oficiales como medio de publicidad, entre otros, los contratos sujetos a regulación armonizada.

Con este nuevo sistema de difusión, aunque prácticamente todas las entidades y centros directivos del sector público ya disponen de ellas, han de tener su propia página web y en ella los órganos de contratación deben tener disponible su perfil de contratante.

El artículo 42.2 deja abierto al criterio de los órganos de contratación el contenido concreto de su perfil de contratante; únicamente obliga, en todo caso, a publicar la adjudicación provisional de los contratos. Entre la información que puede y debe incluirse se encuentra:

- Los anuncios de información previa

- Las licitaciones abiertas o en curso

- La documentación relativa a las mismas

- Las contrataciones programadas

- Los contratos adjudicados

- Los procedimientos anulados

Así como cualquier otra información útil, entre la que la ley sugiere los puntos de contacto o los medios de comunicación que se pueden utilizar para relacionarse con el órgano de contratación.

Además de las cuestiones generales sobre el perfil de contratante definidas en el artículo 42, la ley hace continuas alusiones a lo largo de su articulado a esta cuestión. De esa información dispersa y en lo que a las fundaciones del sector público pudiera afectar, podemos deducir el siguiente esquema:

El perfil del contratante debe contar con una información de carácter permanente y otra de carácter temporal.

En cuanto a la primera, el documento básico son las instrucciones reguladoras del procedimiento de contratación aprobadas por el órgano de contratación (artículo 175. b). También sería recomendable citar el órgano de contratación de la entidad con el nombre de la persona o personas que ostentan la titularidad del mismo. Así como la relación de contratos adjudicados 
ordenados por año y que incorpore la información más elemental de cada uno de ellos: nombre del adjudicatario, importe de adjudicación y plazo de ejecución.

En cuanto a la información de carácter temporal, es la que debe incluir los aspectos relacionados en el artículo 42.2, esto es, la información relativa a cada una de las convocatorias y licitaciones de contratos de cuantía superior a $50.000 €$. De cada uno de los contratos debería facilitarse la siguiente información:

- Anuncio de convocatoria que contenga como mínimo información relativa a: objeto del contrato, tipo de contrato, precio de licitación, plazo de ejecución, procedimiento de adjudicación, plazo y lugar de presentación de ofertas

- $\quad$ Pliego de cláusulas particulares, prescripciones técnicas o documentos descriptivos del contrato, que debe incluir entre otras cuestiones los criterios de adjudicación

- Composición de la mesa de contratación y/ o del órgano de adjudicación y contratación

- Relación de ofertas admitidas a concurso por reunir las condiciones y presentar la documentación requerida

- Preadjudicaciones

- Adjudicaciones

Una vez adjudicado el contrato, toda la información se incorporaría al histórico de contratos adjudicados por la entidad, entrando a formar parte de la información de carácter permanente o estable.

La información relativa a ofertas admitidas, preadjudicaciones y adjudicaciones debe ser motivada y además de su publicación en la web debe acompañarse de comunicación individualizada a cada uno de los interesados.

Por último, y dada la enorme trascendencia que en el campo de la contratación administrativa tienen los plazos, decir que la ley obliga a que el sistema informático que soporta el perfil de contratante cuente con un dispositivo que permita acreditar fehacientemente el momento de inicio de la difusión pública de la información que se incluye en el mismo. 


\section{XII.EFECTOS, CUMPLIMIENTO Y EXTINCIÓN DE LOS CONTRA- TOS}

Esta cuestión la desarrolla el libro IV y tiene como destinatarios únicos y exclusivos, tal y como establece el propio título del libro, los contratos administrativos, quedando fuera los contratos celebrados por las fundaciones del sector público, según la distinción entre contratos administrativos y contratos privados examinada en este texto y regulada en los artículos 18 a 21.

\section{CONCEPTO Y CARACTERÍSTICAS DE LAS FUNDACIONES DEL SECTOR PÚBLICO EN LA LEY 9/ 2007 DE ADMINISTRA- CIÓN DE LA JUNTA DE ANDALUCÍA}

Como decíamos en el capítulo introductorio, como fruto de la casualidad ha coincidido en el tiempo la aprobación de la ley 30/ 2007 con la Ley 9/ 2007 de Administración de la Junta de Andalucía. De la conjunción de ambas normas se obtiene la ansiada definición del régimen jurídico de las fundaciones del sector público andaluz, especialmente en su relación de servicio con la Administración General de la Junta de Andalucía, lo que supondrá un importante avance para agregar seguridad jurídica a su actuación y eficacia a su gestión.

Para definir las fundaciones del sector público andaluz la Ley 9/ 2007 remite a la Ley 10/ 2005 de Fundaciones de la Comunidad Autónoma de Andalucía, por lo que esta cuestión no supone importantes novedades.

La principal novedad hay que buscarla en el artículo 106 de la Ley 9/ 2007 de Administración de la Junta de Andalucía, que dice textualmente:

"L as Consejerías y sus agencias podrán ordenar a las sociedades mercantiles y fundaciones del sector público andaluz cuyo capital o cuya aportación constitutiva, respectivamente, sea en su totalidad de titularidad pública, la ejecución de actividades o cometidos propios de aquellas, siempre que ejerzan sobre ellas un control análogo al que ejercen sobre sus propios servicios y dichas sociedades y fundaciones realicen la parte esencial de su actividad para la Junta de Andalucía.

Las sociedades y fundaciones tendrán la consideración de medio propio instrumental de la Administración de la Junta de Andalucía o de sus agencias, a los efectos de la ejecución de obras, trabajos, asistencias técnicas y prestación de servicios que se les en comienden.

La encomienda de dichas actividades no podrá implicar, en ningún caso, la atribución de potestades, funciones o facultades sujetas a Derecho Administrativo". 
Este artículo hay que estudiarlo en relación con los artículos 4.1.n) y 24.6 de la ley 30/ 2007:

El artículo 4 enumera los contratos excluidos del ámbito de aplicación de la ley entre los cuales se encuentran (apartado $\mathrm{n}$ ) los negocios jurídicos en cuya virtud se encargue a una entidad que tenga atribuida la condición de medio propio y servicio técnico del mismo, la realización de una determinada prestación.

El artículo 24.6, por su parte, define las características que han de tener los entes, organismos y entidades para ser consideradas medio propio o servicios técnicos de los poderes adjudicadores:

"A los efectos previstos en este artículo y en el artículo 4.1.n), los entes, organismos y entidades del sector público podrán ser considerados medios propios y servicios técnicos de aque llos poderes adjudicadores para los que realicen la parte esen cial de su actividad cuando éstos ostenten sobre los mismos un con trol análogo al que pu eden ejercer sobre sus propios servicios. Si se trata de sociedades, además, la totalidad de su capital tendrá que ser de titularidad pública.

En todo caso, se en ten derá que los poderes adju dicadores ostentan sobre un ente, organismo o entidad un control análogo al que tien en sobre sus propios servicios si pueden conferirles en comien das de gestión que sean de ejecución obligatoria para ellos de acu erdo con instrucciones fijadas unilateralmente por el encomendante y cuya retribución se fije por referencia a tarifas aprobadas por la entidad pública de la que dependan.

La condición de medio propio y servicio técnico de las entidades que cumplan los criterios mencionados en este apartado deberá reconocerse expresamente por la norma que las cre 0 por sus estatutos, que deberán determinar las entidades respecto de las cuales tien en esta condición y precisar el régimen de las en comiendas que se les puedan conferir o las condiciones en que podrán adjudicárseles con tratos, y determinará para ellas la imposibilidad de participar en licitaciones públicas convocadas por los poderes adjudicadores de los que sean me dios propios, sin perjuicio de que, cuando no con curra nin gún licitador, pueda encargárseles la ejecución de la prestación objeto de las mismas."

El tratamiento de esta cuestión en ambas normas responde a la aplicación efectiva de la jurisprudencia del Tribunal de Justicia Europeo, en aplicación de la denominada doctrina "in house providing", relativa a los contratos celebrados por una entidad adjudicadora con determinados organismos públicos vinculados a ella. Los límites de esta excepción se detallaron, en particular, en las sentencias de 18 de noviembre de 1999, Teckal (C-107, Rec I-8121) y de 7 de diciembre de 2000, ARGE Gewässerschutz (C-94-99, Rec. I-11037). Ambas sentencias establecen los requisitos para que un contrato o la realización de una determinada prestación entre un poder adjudicador y un ente instrumental a él vinculado, se pueda adjudicar directamente a favor del ente ins- 
trumental sin aplicación de la legislación de contratos. Los requisitos exigidos son:

- Que el poder adjudicador ejerza sobre el ente de que se trate un control análogo al que ejerce sobre sus propios servicios.

- Que este ente realice la parte esencial de su actividad con el ente ( poder adjudicador) que lo controla.

La legislación española añade un tercer requisito.

- Que si el ente del que se trata es una sociedad, además, la totalidad de su capital tendrá que ser de titularidad pública. En relación a este requisito la legislación andaluza añade: “... cuyo capital o cuya aportación constitutiva, respectivamente, sea en su totalidad de titularidad pública", de lo que se deduce que está extendiendo el requisito a lasfundaciones del sector público.

De la regulación expuesta se pueden extraer las siguientes conclusiones en relación con las fundaciones del sector público andaluz:

- Las fundaciones del sector público son medio propio de la Administración de la Junta de Andalucía, siempre que cumplan los requisitos establecidos en la legislación.

- Las fundaciones del sector público andaluz pueden recibir encomiendas de gestión de cualquier órgano de la Administración de la Junta de Andalucía o de sus agencias, sin que se restrinja tal posibilidad a la Consejería o centro directivo del que dependa.

- Para realizar la encomienda el poder adjudicador encomendante no tendrá que tener en cuenta las normas establecidas en la ley 30/ 2007 ni en las directivas comunitarias que, en principio le fueran de aplicación, al estar haciendo uso de un medio propio, lo que se ha venido en llamar autocontratación o "house providing".

- El procedimiento para formalizar la encomienda de gestión será el establecido en el artículo 25.6 de la ley de Presupuestos de la Comunidad Autónoma de Andalucía para 2008.

- No obstante lo anterior, los contratos que deban celebrarse por las fundaciones del sector público andaluz para la realización de las prestaciones objeto del encargo quedarán sometidos a la Ley de Contratos, en los términos que sean procedentes de acuerdo con la naturaleza de la entidad que los celebre y el tipo y cuantía de los mismos. 
- Las actividades o prestaciones que les sean encomendadas a una fundación del sector público andaluz por la Administración de la Junta de Andalucía o sus agencias son irrenunciables y de obligada realización.

- Se hace necesario una adaptación de los estatutos de las fundaciones para recoger en ellos los extremos exigidos en el artículo 24.6: “... la condición de medio propio y servicio técnico de las entidades que cu mplan los criterios men cionados en este apartado deberá reconocerse expresamente por la norma que las cree o por sus estatutos, que deberán determinar las entidades respecto de las cuales tien en esta condición y precisar el régimen de las en comiendas que se les puedan conferir o las condiciones en que podrán adjudicárseles contratos...".

- Las fundaciones del sector público andaluz no podrán participar en licitaciones públicas convocadas por la Administración de la Junta de Andalucía. 